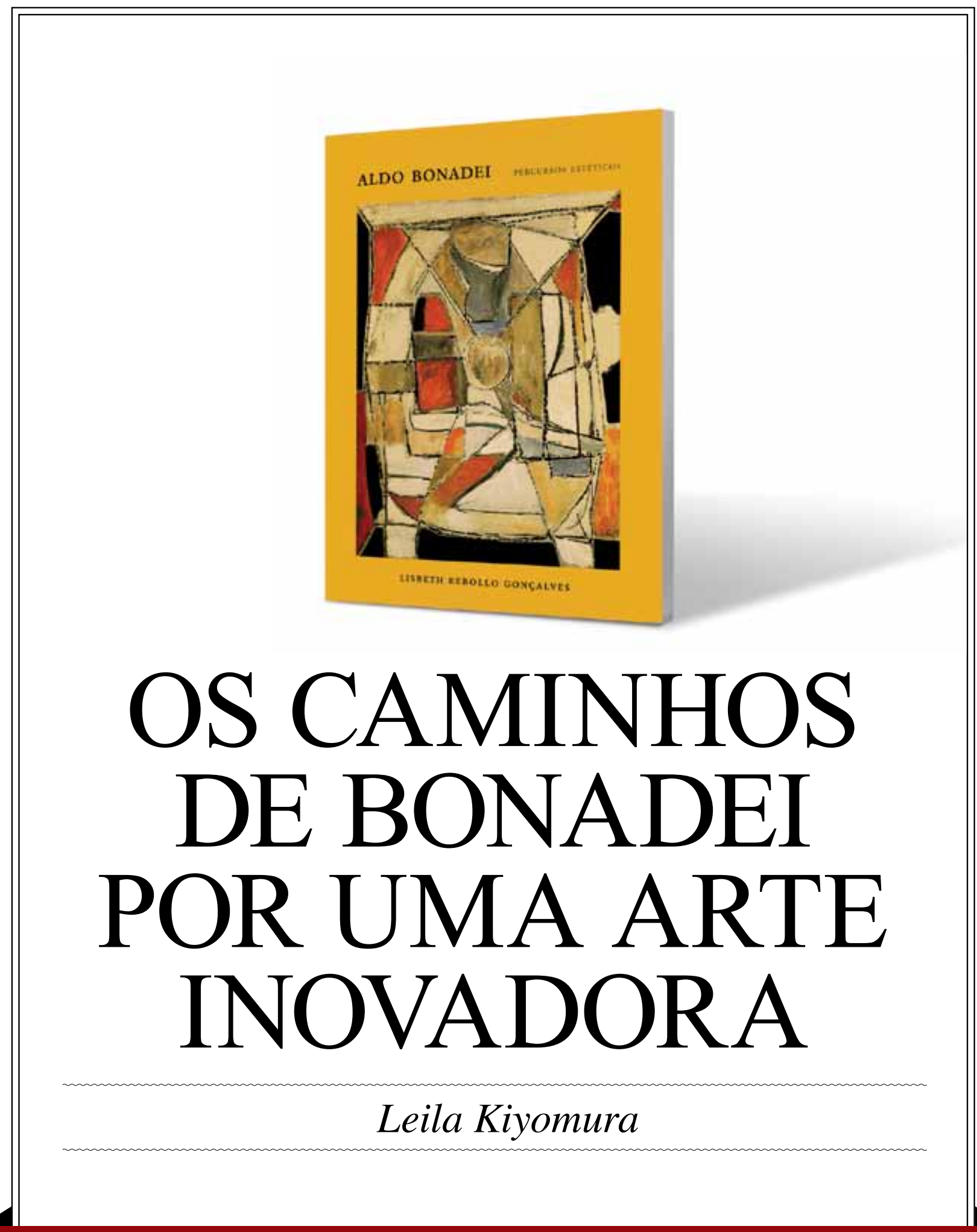

ALDO BONADEI: PERCURSOS ESTÉTICOS, DE LISBETH REBOLLO GONÇALVES,

$$
\text { SÃO PAULO, EDUSP/IMPRENSA OFICIAL, 2012, } 296 \text { P. }
$$




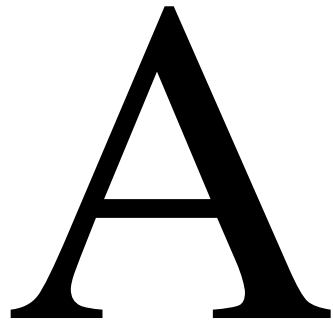

companhar o cotidiano de Aldo Bonadei no questionamento incessante da sua própria arte é o desafio da professora, historiadora e crítica de arte Lisbeth Rebollo Gonçalves. O livro Aldo Bonadei: Percursos Estéticos, lançado pela Edusp e Imprensa Oficial, alia a pesquisa à história, fundamentando a arte como forma de pensamento.

Enquanto observa o pintor mergulhando entre sonhos e emoções para revelar paisagens sempre em busca de algo novo, a autora imprime o tempo do artista na história da arte brasileira. Logo no primeiro parágrafo das 296 páginas, Lisbeth justifica a importância de pesquisar o artista: "Percorrer a obra de Aldo Bonadei é, de certa forma, percorrer um trecho significativo da história da arte moderna de São Paulo e do país”. Uma história que a autora vai compondo através de cada tela e das indagações que o transformaram em um dos pioneiros da arte abstrata brasileira. "Se, por um lado, temos em Bonadei um pintor adaptado ao quadro histórico da consolidação de arte moderna, por outro, deparamos com uma personalidade lúdica, intuitiva e aberta a pesquisas e experiências incomuns naquele momento".

É essa personalidade, que se apresenta desde a iniciação precoce na pintura, que o leva a buscar uma arte própria, porém, atenta aos acontecimentos do mundo. E vai por caminhos diversos deixando fluir a sua inventividade. "Bonadei tem um temperamento indagador, que busca motivação e interesse em outras áreas artísticas - música, poesia, literatura, cinema, teatro, dança, mímica - e que se interessa pela relação entre os problemas de percepção e da ciência pela construção do espaço pictórico", explica a autora. "Enfim, é um pesquisador aberto a todas as informações que possam auxiliar na compreensão e desenvolvimento da criação artística."

Lisbeth segue o artista com suas indagações estéticas em cada fase. Tarefa difícil, já que o pintor é o seu maior crítico. Repensa a pintura, fechando e abrindo cada etapa em círculos. A autora também vai por diversos caminhos, pesquisando não só a pintura, mas os seus escritos, depoimentos, detalhes do ateliê, fotografias. Reúne documentos que revelam o ambiente artístico e intelectual de Bonadei. E consegue apresentar um apanhado histórico-cronológico de sua formação artística, esforçando-se, como ela própria argumenta, para apreender cada estágio de seu aprendizado.

O leitor encontra Bonadei diante de suas telas refletindo sobre os problemas da cor, dos planos, da profundidade, do desenho. "Durante 25 anos, segue-se com nitidez o enriquecimento gradativo do seu universo plástico; nos trinta anos seguintes, no entanto, a pesquisa abstração-figuração domina, com exclusividade, as preocupações do pintor", observa Lisbeth. "Para focalizar esse período, em que o artista já apresenta uma expressão pictórica bem definida e tenta extrair do diálogo abstração-figuração um encaminhamento pessoal, achamos mais produtivo fixarmo-nos numa abordagem concentrada na análise do espaço plástico."

\section{PEQUENA VÍRGULA}

Em uma frase dita em 1973, Aldo Bonadei sintetiza a sua trajetória: "Trabalhei tantos anos sem conseguir fazer alguma coisa nova. No entanto, de uns quatro ou cinco anos para cá, acredito que consegui fazer alguma coisa. Tenho até medo de dizer, mas acho que descobri uma nova abertura. Talvez uma pequena vírgula, em se comparando com o todo".

Por essa pequena vírgula, o pintor dedicou a vida. Lisbeth traz a história do menino de nove anos pintando, em 1915, Goiabas, o seu primeiro óleo sobre tela. São três frutos verdes ainda presos aos seus galhos destacados por um fundo marrom. Na assinatura "ABonadei" - registrada com tinta vermelha, a primeira impressão do futuro pintor. "Daí para frente, as pesquisas de desenho e pintura se sucedem. Realiza pequenas paisagens, retratos, naturezas-mortas, tenta a composição com figuras. Caminha autodidaticamente até 1923, quando o pai, aceitando sua
LEILA KIYOMURA é jornalista do Jornal da USP e coautora de Ateliês Brasil - Artistas Contemporâneos de São Paulo (Empresa das Artes) e Claudio Tozzi (Edusp). 

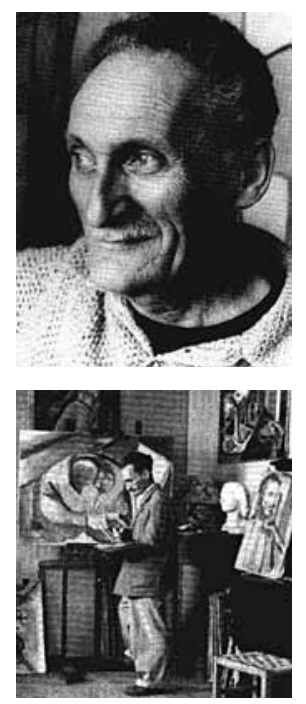

Acima, retrato de Bonadei; abaixo, o artista em Moema (1937-40) vocação, o envia a um dos mais afamados mestres de pintura de São Paulo, o pintor Pedro Alexandrino", conta Lisbeth.

Durante cinco anos, Bonadei aprende o exercício do desenho e a disciplina da composição. "Pedro Alexandrino não abordava os problemas de cor e do uso da paleta. Considerava prejudicial que tentasse, de imediato, realizar um quadro. Para chegar aos pincéis, o caminho a percorrer era longo e o mestre não aceitava curiosidades", explica a autora. "Bonadei acatava Alexandrino durante as aulas. Numa das primeiras, o exercício consistia em desenhar um tijolo, de todos os ângulos de visão. Posteriormente, confiava ao aluno desenhos-padrão, que trouxera da Academia Julian, de Paris, para que exercitasse a cópia, que podia ser repetida várias vezes, se o mestre não aprovasse o resultado. Num terceiro estágio, passavam a desenhar a partir de modelos de gesso [...]".

Às escondidas, longe da autoridade do professor, o artista desenvolvia as suas próprias experiências, pintando paisagens, naturezas-mortas e retratos. "De Alexandrino, Aldo Bonadei parece ter assimilado, principalmente, a disciplina de trabalho e a racionalização de composição com o conhecimento correto do desenho e a elaboração ordenada de estrutura do quadro."

Lisbeth pesquisa o período de formação e consegue resgatar paisagens de 1927 , como Barcos, que documenta a visão do artista da Baía da Guanabara. Lembra os anos de 192930 , quando conhece o professor e amigo Amadeo Scavone com quem, segundo o artista, aprendeu a pensar e estruturar as formas, linhas e cor. Nessa época, Bonadei decide partir para a Itália. "De regresso ao Brasil, em agosto de 1931, enriquecido com o estágio em Florença, o artista caminha para um período de transição, integrando o Grupo Santa Helena."

\section{O PINTOR E A CIDADE}

A autora contextualiza a história de Aldo Bonadei com a da cidade de São Paulo. Lembra os movimentos culturais da época. "A década de 1940 é marcada por uma atuação significativa dos artistas plásticos, em continuidade ao processo de consolidação da arte moderna, iniciado nos anos de 1930."

Lisbeth destaca, em fins de 1946, a inauguração da primeira galeria de arte moderna de São Paulo, a Domus. Em 1947, é fundado o Museu de Arte de São Paulo e, no ano seguinte, o Museu de Arte Moderna de São Paulo. Lembra também a importância de uma divisão do Salão Nacional de Belas Artes do Rio de Janeiro que premia os artistas com bolsas de estudos no exterior. "Ao mesmo tempo, ao lado da geração emergida nos anos de 1940, que prossegue suas pesquisas e luta pela conquista definitiva de um lugar, vemos surgir um novo grupo de artistas e intelectuais que acentuam a presença do modernismo em nosso cenário cultural."

A influência da Segunda Guerra Mundial estimula o crescimento industrial e a modernização dos padrões de vida. Os empresários passam a incentivar a arte moderna. "É sintomático que, logo no princípio da década, em 1941, a II Feira Nacional das Indústrias abra ao público, em seu recinto, um salão de arte moderna. Ao final do decênio, os meios industriais dão seu apoio inaugurando a Bienal, ligada ao MAM, três anos mais tarde."

Ao mesmo tempo em que se debate com as suas indagações estéticas particulares, Bonadei se une à luta dos artistas pela afirmação de novas linguagens nas artes plásticas. O pintor, segundo a autora, é visto como representante do Grupo Santa Helena e da pintura paulista.

\section{UM NOVO ESPAÇO}

As raízes do abstracionismo bonadeiano são investigadas por Lisbeth na sua fase de experiências de música e pintura. O pintor tenta captar graficamente as sensações que a música de Beethoven proporciona. "Num primeiro momento, a vibração dos sons é expressa por meio da sinuosidade assumida pela linha, por esferas em espiral, por traços realizados a partir de um impulso espontaneamente provocado pela música. Desses movimentos lineares, concêntricos, ziguezagueantes, resulta uma forma no espaço, forma e espaço registradores 
de energia interna que guia a mão do artista. $\mathrm{Se}$, de imediato, resulta uma simbologia geométrica, a posteriori o artista depreende uma essencialidade abstrata de construção que começa a guiá-lo quando pensa na realidade."

Ao citar a fase do gesto e lirismo do artista, a professora reflete sobre as mudanças no ver e entender a arte da época. "A arte abandona as dimensões tradicionais e estabelece um novo espaço; abole a forma naturalista $\mathrm{e}$ a determinação da imagem numa amplitude definida. Afirma uma nova presença do ser na atividade e estabelece, portanto, uma nova ontologia. Não é uma arte contra a sociedade contemporânea ou a pintura contemporânea, não é a afirmação de uma antipintura como, por exemplo, o dadaísmo. Trata-se, para além de qualquer fórmula racional, da individualização do senso de realidade do artista."

As dúvidas de Cézanne sobre os seus caminhos na arte influenciam Bonadei. Ambos recorrem à pintura a partir do natural. "A paisagem ou natureza-morta são vividas e dialogadas, antes de se tornarem motivo de um quadro. Já não é mais a natureza, como realidade, que procura retratar com habilidade que leva ao máximo de semelhança e precisão, mas ela é o sujeito a partir do qual a forma se elabora e o artista se expande em novas interrogações."

Lisbeth busca o olhar de Bonadei sobre a arte de Cézanne. Uma pesquisa delicada, traçando paralelos sutis entre a inquietude e a organização de ambos na definição do espaço pictórico. Uma análise cuidadosa que levanta hipóteses para pesquisas mais aprofundadas. "Há momentos diversos que implicariam respostas diferentes [...]", observa. "Verificamos, no caso de Bonadei, como às vezes também se dá em Cézanne, a ocorrência de uma determinação de planos ou áreas mais amplas, fundamentais, que se destacam do plano base da tela, como a sugerir uma continuidade do espaço extraquadro, a partir do próprio quadro."

Depois de registrar o pensamento do artista em todas as fases, Lisbeth vai rastreando a volta de Bonadei à figuração. "No momento de síntese, após prolongados esforços
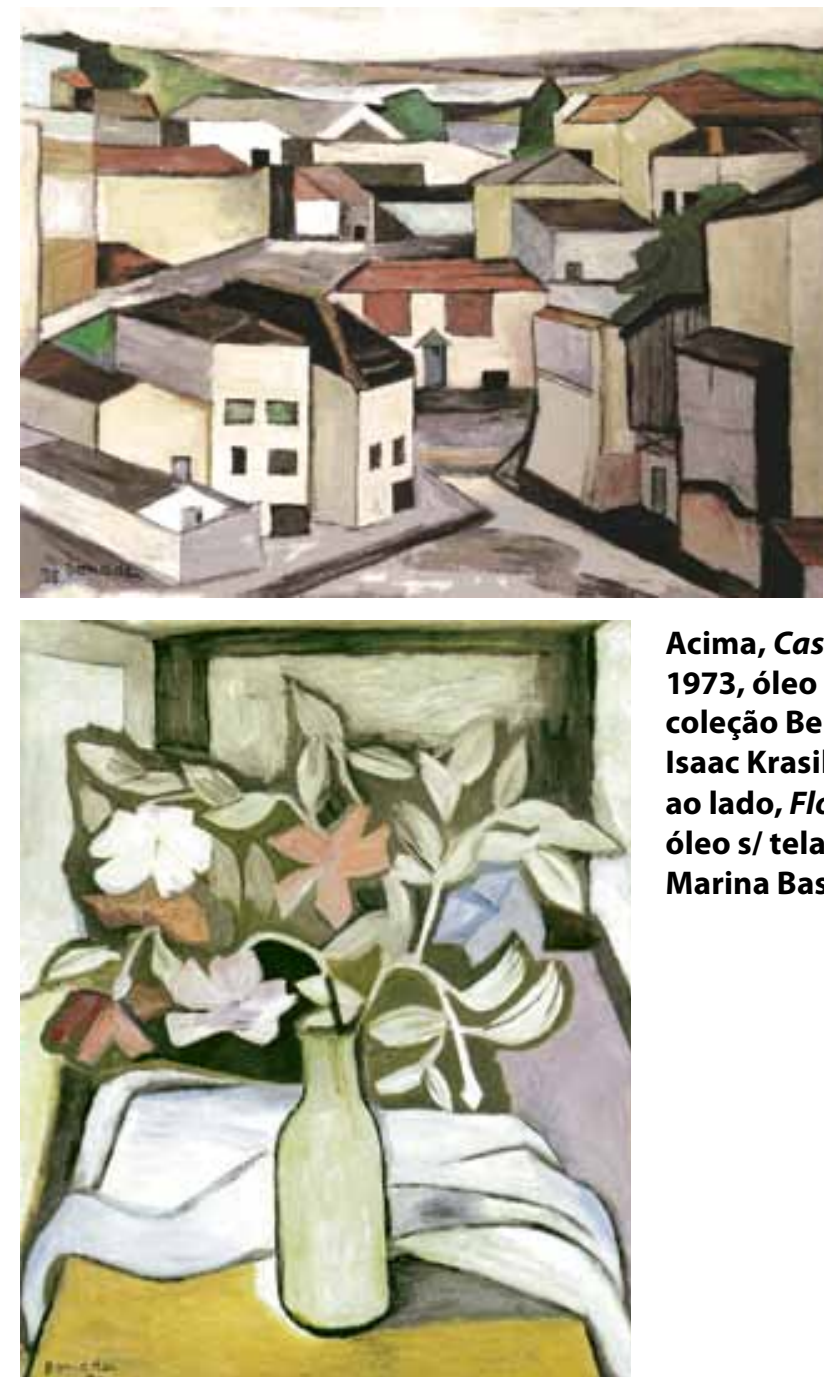

Acima, Casario, 1973, óleo s/ tela, coleção Bertha e Isaac Krasilchik; ao lado, Flores, 1970, óleo s/ tela, coleção Marina Basile

de pesquisa, a figuração bonadeiana aparece com outra função: surge como uma articulação entre os fenômenos de percepção formal e os mistérios da emoção, que faz vibrar o pintor e o leva a pintar."

Bonadei depara-se com "a pequena vírgula" que tanto buscava. "Na síntese de razão-lirismo, de figuração-abstração, configura-se a especificidade da assimilação que o artista desenvolve no contato com as principais lições estéticas de nosso século", conclui a autora.

No caminho da arte brasileira, fica a orientação de Aldo Bonadei: "O melhor é deixar que a mente siga seus próprios conselhos e ensinamentos, suas próprias intuições... Toda regra de que o discípulo não possa se afastar é uma grande barreira". 